\title{
Sperm Transcriptomics: An Emerging Technique to Assess Male Fertility
}

\author{
Kennady Vijayalakshmy ${ }^{1 *}$, Dharmendra Kumar ${ }^{2}$, Meenakshi Virmani ${ }^{3}$, \\ Ninan Jacob ${ }^{1}$ and Pradeep Kumar ${ }^{2}$ \\ ${ }^{1}$ Department of Veterinary Physiology, Rajiv Gandhi Institute of Veterinary Education and \\ Research, Kurumbapet, Puducherry-605 009, India \\ ${ }^{2}$ Department of Animal Physiology and Reproduction, ICAR-Central Institute for Research on \\ Buffaloes, Hisar-125004, Haryana, India \\ ${ }^{3}$ Department of Veterinary Physiology, Lala Lajpat Rai University of Veterinary and Animal \\ Sciences, Hisar-125004, Haryana, India \\ *Corresponding author
}

\section{A B S T R A C T}

\section{Keywords \\ Fertility markers, Male infertility, Semen, Sperm mRNA, Transcriptome analysis \\ Article Info \\ Accepted: 08 August 2018 Available Online: 10 September 2018}

Semen sample has to be analyzed to determine the fertilization capacity of sperm. This helps in the efficient use of semen sample for cryopreservation and their further use in artificial insemination. The current methods used to analyze semen just indicate a predictive fertility status, not an actual fertilization capacity. Certain mRNA population / transcripts which are present in spermatozoa are found to have a potential role in fertilization capacity. The analysis of mRNA population in sperm by means of isolation of RNA from sperm and profiling of these mRNA transcripts may give the actual fertilization status of the sperm. This technique is non-invasive in nature and it can be used as promising technique to screen the fertility of male animals at an early stage.

\section{Introduction}

The fertility assessment of frozen-thawed semen is essential for the effective use of cryopreserved semen in animal breeding. The laboratory evaluation of semen from healthy male animals, before and after freezing for artificial insemination (AI), is largely based on subjective analysis of sperm motility and concentration. Hence, an accurate and efficient in vitro method is warranted to predict fertility, especially of buffalo sperm. This will help to select the future breeding male stock at an earlier age of maturity. However, the information pertaining to the fertility index in relation to sperm attributes is meager. The factors associated with high fertility in male animals help in designing better strategy for improving the field fertility of male animals following insemination with frozen-thawed semen.

Another important concern in animal breeding is sub-fertility, which even today remains as a non-predictable measure in case of many animals. Evaluation of fertility is primarily by 
calculating the non-return rate (NRR). The male animals that are retained generally have an NRR that varies from 20-25\% (Killian et al., 1993). A number of methods are used to correlate the fertility potential of a sire, measured in vitro, with the NRR in order to reduce the costs associated with subfertility. The selection of sires for species reproduction requires an in vivo evaluation of fertility that is carried out over a period that can run from several months to several years. During this period, the semen has already been treated and stored with a view of eventual marketing. The process involves the handling of thousands of ejaculates, their cryopreservation and breeding attempts that all incur significant costs. The new molecular detection tools that have been developed as a result of recent developments in the field of comparative genomics and global gene expression analysis, will allow a number of parameters to be effectively integrated into the evaluation of the fertilizing potential of semen.

The presence of RNA in spermatozoa is well established, yet little is known regarding its function and purpose (Dadoune et al., 2005; Selvaraju et al., 2017). A decade back, RNA in the sperm was believed to be nonfunctional. It is now known that RNA might perform active functions in the embryo development and fertilization (Ostermeier et al., 2004); establishment and maintenance of a viable paternal genome (Miller et al., 2005); activation of embryonic genome (Boerke et al., 2007); fertilization (Yao et al., 2014); regulate expression of their parent gene in the male germline (Jodar et al., 2015), pregnancy outcome (Kasimanickam et al., 2013) and may also influence the phenotype of the offspring (Rando, 2012). Rassoulzadegans et al., (2006) provided a model for epigenetic inheritance by zygotic transfer of RNAs that dysregulate expression of c-Kit gene, which leads to the modification of phenotypic expression of the offspring. Sperm RNA could be available as a diagnostic tool for male infertility (Jodar et al., 2012; Millar et al., 2014) and also determine the quality of semen (Das et al., 2013; Georgiadis et al., 2015; Parthipan et al., 2015). This finding sparked considerable interest in the field since such a potential contribution of the male gamete to embryonic development challenged the well accepted dogma, which restricted the male gamete to a DNA shuttling vector. To elucidate these functions of transcripts retained in sperm, approaches like microarrays, RNA-Seq, qRTPCR have been applied (Carreau et al., 2007; Platts et al., 2007; Yang et al., 2009; Jodar et al., 2012; Lima-Souza et al., 2012; Card et al., 2013). Success of these technologies is dependent on the quality of the RNA obtained. Quality sperm RNA isolation depends on the purity of spermatozoa which should be free from somatic cells contamination.

Though the male animals form an integral part of livestock agriculture but lower conception rate of AI with frozen semen, is mainly due to the susceptibility of spermatozoa to hazards during freezing-thawing process. It is well documented that cryopreservation induces sperm damage owing to the rapid change in low temperature which leads to mechanical damage to plasma membrane, metabolic alteration, oxidative stress to phospholipid membrane, DNA damage and eventually reduced fertilizing capacity. Traditionally a number of methods are available for evaluation of semen quality in laboratory like assessment of the integrity of genomic DNA, acrosome and plasma membrane and mitochondrial as well as sperm-oocyte interactions. But, the development of a reliable method for routine isolation of high quality RNA from sperm will be an important step to develop novel non-invasive approach to evaluate male fertility. The RNA transcript may have important roles in sperm development, chromatin repackaging, genomic imprinting, capacitation, acrosome 
reaction and early embryonic development. Understanding the make-up of sperm RNA transcripts may prove to be important in understanding the events surrounding capacitation, motility, fertilization and ultimately in explaining the male fertility. The development of new investigative method such as analysis of mRNA profile in sperm and understanding the significance of the transcripts would be helpful as additional diagnostic tool and be of prognostic value to fertilization and establishment of pregnancy.

\section{Historical perspective of sperm RNA}

The existence of spermatozoal RNAs was formerly examined based on the postulation that termination of transcription process takes place in round spermatid stage, where there is removal of cytoplasm and the components which are necessary for translational activity is absent. Hence, the remaining male haploid RNA which is present would be insignificant. This view was supported by the observed heterogeneity of the ejaculate, the presence of somatic cell contaminants which accounted for the majority of large RNAs in most samples and the absence of intact ribosomal RNAs. These caveats partly reflected the inadequacy of the methods that were available to purify spermatozoa and to detect low abundance RNAs (Krawetz, 2005). The controversy was resolved when several laboratories independently identified specific sperm RNAs in plants (Rejon et al., 1988) and in mammals, including rat (Pessot et al., 1989), mouse (Wykes et al., 2000) and human (Kumar et al., 1993; Miller et al., 1994; Wykes et al., 1997) using RT-PCR and in situ hybridization. Above mentioned studies demarcated the existence of RNA in mature sperm nucleus and later studied the paternal contribution in fertilization and embryo development. Persistence of a low but detectable level of transcription in mature sperm cells has also been reported by Miteva et al., (1995). Up to now, human spermatozoal transcripts are regarded as the best detectable amongst all mammals.

The RNA profile of human spermatozoa was initially attempted using a cDNA cloning and sequencing strategy (Miller et al., 1999) which was followed by select RT-PCR (Lambard et al., 2004). But, these methods were able to investigate only a small fraction of all potential transcripts. The first general spermatozoal RNA profiles were obtained using microarrays, which suggested that human spermatozoa contain $\sim 3000-7000$ different coding transcripts (Ostermeier et al., 2002). This was subsequently protracted to the clinic with the assessment of specific transcripts in cases of asthenozoospermia in humans (Jodar et al., 2012), teratozoospermia in humans (Platts et al., 2007), oligozoospermia in humans (Montjean et al., 2012) and idiopathic infertile males in humans (Garrido et al., 2009). Their ability to serve as potential biomarkers of fertility was highlighted. Transcript profiling of coding RNAs using microarrays in conjunction with RT-PCR has nowadays broadly defined the abundance of known sperm transcripts in other mammals (Gilbert et al., 2007; Bissonnette et al., 2009; Yang et al., 2010) and nonmammalian species like plants (Borges et al., 2008) and Drosophila Melanogaster (Fischer et al., 2012). In comparison to the abovementioned statement, RNA-Seq has provided a complete picture of the population of sperm transcripts, allowing for the identification, quantification and characterization of both known and previously unknown RNAs (Sendler et al., 2013; Selvaraju et al., 2017). These studies highlighted the selective retention of a cadre of both coding RNAs and small non-coding RNAs in all individuals studied. In recent times, many scientists have initiated in employing RNA-Seq to examine the distribution of sperm RNAs in bovine (Card et al., 2013; Selvaraju et al., 2017), 
stallion (Das et al., 2013) and the small RNA population of mouse (Kawano et al., 2012; Peng et al., 2012).

\section{Derivation of sperm RNA during spermatogenesis}

Spermatogenesis is the process where there is development of spermatozoa from spermatogonium in the seminiferous tubules. This process is more or less similar in all mammalian species. The process of spermatogenesis is mainly classified into three phases depending upon their functional considerations:

\section{Spermatocytogenesis}

Mitotic phase / Proliferative phase (Equational division): Mitosis of undifferentiated spermatogonium occurs.

Meiotic phase (Reductional division): Primary spermatocyte yields two secondary spermatocytes (A1-A4; B Spermatogonia), by means of undergoing meiosis I, whereas secondary spermatocytes (B-spermatocytes) again go for meiosis II to yield four haploid round spermatids.

A- Spermatogonia have the potential to go back to its preceding stage of undifferentiated Spermatogonia, by means of renewal of stem cell. The round spermatids enter into a final phase of spermatogenesis called differentiation phase.

Spermiogenic phase (Differentiation / Metamorphosis): Here the actual differentiation of spermatid to become complete spermatozoa, which is equipped to cause fertilization, occurs. The series of changes include the morphological transformations where in the fully functional head and tail is formed to become a complete spermatozoon.
During proliferation and meiosis, expression is chiefly under transcriptional control. Transcriptional control also applies to the early haploid stages of spermatogenesis, and indeed, Meiosis I prophase is when many of the RNAs that will be translated postmeiotically are transcribed. Their translation corresponds with nuclear shutdown. The fate of these transcripts is suggested, with most of the pre-meiotic and early meiotic RNAs going into the residual bodies. Selected premeiotically transcribed RNAs and haploidexpressed transcripts are then retained by the spermatozoa. This relationship has not been experimentally proved.

However, mRNA in sperm may be residual, which reflects the transcription shutdown during the process of spermiogenesis. Developing spermatids solely depends on mRNA stores for long time, because they require translational control of gene expression, whereas spermatids may mislay the ability to exclude it from maturing cell (Miller and Ostermeier, 2006). The equal sharing in case of gene products by means of developing spermatids is preferred by a common block on exclusion pathways of RNA. This process is maintained with the help of incessant presence of cytoplasmic bridges which interconnects spermatids (Caldwell and Handel, 1991). Further, absence of sufficient $28 \mathrm{~S}$ or $18 \mathrm{~S}$ rRNAs (80s ribosomal complexes) in mature spermatozoa for supporting transition, signifies their breakdown or elimination during the course of spermatozoal evolution (Miller et al., 1999).

\section{Sperm and its types of RNA}

Sperm is a remarkably differentiated cell whose prime function is to deliver the paternal haplotype to the ovum. Despite this, sperms are extremely variable in form, with all aspects of the sperm phenotype showing high levels of variation (Pitnick et al., 2009). The 
fact that sperm has until now been presumed to only contribute DNA (plus structures such as centromeres) to eggs, makes the recent discovery of a complex sperm RNA population (Miller et al., 2005; Boerke et al., 2007; Fischer et al., 2012), surprising and hard to explain. The RNA population carried by sperm is large and varied. It includes messenger RNA (mRNA), micro RNA (miRNA), interference RNA (iRNA), and antisense RNA (Dadoune, 2009). These include transcripts for heat shock proteins, cytochrome $\mathrm{P} 450$ aromatase, and a range of receptors, including odour receptors (Dadoune, 2009). Sperm RNA is unlikely to be transcribed from sperm nuclear DNA because of the changes in chromatin structure that occur when protamine replaces histones during sperm DNA compaction. Hence, it was originally thought that sperm RNAs were simply remnants of spermatogenesis (Curry et al., 2011). However, various evidences suggests that sperm RNAs are not merely discards from the sperm-building process. First, there are indications of translational activity in the sperm cells, using sperm RNA as the substrate (Fischer et al., 2012). Second, there is evidence that sperm RNA contributes to fertilization and to embryo development (Liu et al., 2012). All this infers that the presence of sperm RNA has fitness consequences for both males and females, and is there because of its adaptive value. However, unequivocal evidence of precise sperm-RNA contains thousands of transcripts which function is rare or completely unknown.

\section{Location and nature of sperm RNA}

It has long been apprehended that the tightly packaged chromatin within mature spermatozoa is transcriptionally inert. Despite this, RNA was observed in the mature sperm nucleus of fern Scolopendrium (Rejon et al., 1988) and in rodents and other species (Pessot et al., 1989; Concha et al., 1993). When subjected to acrylamide electrophoresis, the RNA described by Pessot et al., (1989) was found to resolve into discrete bands that included 5.8S and 5S RNAs as well as tRNAs.

This and the advanced report by Concha et al., (1993) localizing U1 and U2 small nuclear RNAs were the first to provide visual information on the localization of spermatozoal RNA to the nucleus. Consequently, Kumar et al., (1993) reported the presence of $c$-myc mRNA in the principal piece of human spermatozoa, and a few years later, two independent reports indicated the presence of protamine 2 mRNA by RT-PCR and in situ hybridization, with the later also localizing the RNA to the nucleus (Miller, 1997; Wykes et al., 1997). These reports support the localization of spermatozoal RNA in or around the nucleus.

However, spermatozoa contain a complex range of RNAs, but meager information is available to indicate storage position of RNA within the cells. There are four main segments of a mature spermatozoon. As suggested by various studies, the perinuclear theca and the post-acrosomal sheath are the possible areas for spermatozoal RNA repositories. Additionally, Kumar et al., (1993) have localized transcripts to present within the midpiece. Again, the fibrous sheath and axoneme may also tend to carry spermatozoal RNA.

\section{Amount of RNA available in spermatozoa}

The RNA quantity in a sperm cell is very low; one haploid spermatozoon contains $~ 10-20 \mathrm{fg}$ of RNA, compared to $450 \mathrm{fg}$ of RNA in a haploid spermatid and $~ 10-20$ pg of RNA in one diploid somatic cell (Krawetz, 2005; Carreau et al., 2007; Galeraud-Denis et al., 2007). The amount of RNA in spermatozoon is varying between individual species; which is indicated in the Table 1. 
Table.1 RNA yield/spermatozoon in various species

\begin{tabular}{|l|l|l|}
\hline \multicolumn{1}{|c|}{ Species } & \multicolumn{1}{c|}{ RNA yield $(\mathrm{fg}) /$ spermatozoon } & \multicolumn{1}{c|}{ Refence(s) } \\
\hline Human & $10-20$ & Ostermeier et al., 2005 \\
\hline Human & $50-100$ & Goodrich et al., 2007 \\
\hline Cattle & $20-31$ & Card et al., 2013, Selvaraju et al., 2017 \\
\hline Cattle & 180 & Gilbert et al., 2007 \\
\hline Horse & 20 & Das et al., 2013 \\
\hline Pig & $5-10$ & Boerke et al., 2007 \\
\hline Rat & 100 & Pessot et al., 1989 \\
\hline
\end{tabular}

Table.2 List of mRNA transcripts present in spermatozoa of various species

\begin{tabular}{|c|c|c|c|c|}
\hline S. No & Species & $\begin{array}{c}\text { mRNA } \\
\text { Transcripts }\end{array}$ & Cell Type & References \\
\hline & Bovine & & & \\
\hline 1 & & $\begin{array}{l}\text { Cadherin 15, EST, } \\
\text { PABPC4, PABPN1 }\end{array}$ & Spermatozoal cells & $\begin{array}{l}\text { Lalancette at al., } \\
2008\end{array}$ \\
\hline 2 & & PRM1, PRM2 & Spermatozoal cells & $\begin{array}{l}\text { Bissonnette et al., } \\
2009\end{array}$ \\
\hline 3 & & $\begin{array}{l}\text { PRM1, PRM2, } \\
\text { PRM3, Tnp1 and } \\
\text { Tnp2 }\end{array}$ & Testicular cells & Ferraz et al., 2010 \\
\hline 4 & & $\begin{array}{l}\text { CRISP2, PEBP1, } \\
\text { CCT8, BRP }\end{array}$ & Spermatozoal cells & $\begin{array}{l}\text { Arangasamy et al., } \\
2011\end{array}$ \\
\hline 5 & & $\begin{array}{l}\text { PRM1, } \\
\text { LOC783058, } \\
\text { HMGB4, } \\
\text { LOC404073, } \\
\text { KIF5C, TMSB4X, } \\
\text { GSTM3 }\end{array}$ & Spermatozoal cells & Card et al., 2013 \\
\hline 6 & & $\begin{array}{l}\text { Protamine } 1, \\
\text { Protamine } 2\end{array}$ & Spermatozoal cells & $\begin{array}{l}\text { Ganguly et al., } \\
2013\end{array}$ \\
\hline 7 & & $\begin{array}{l}\text { CCT5, GUK1, } \\
\text { CTRB1, SRMS, } \\
\text { ISCU, PJA1 }\end{array}$ & Spermatozoal cells & Yathish et al., 2016 \\
\hline 8 & & $\begin{array}{l}\text { MIR708, VSNL1, } \\
\text { SQRDL, CD28 }\end{array}$ & Spermatozoal cells & $\begin{array}{l}\text { Selvaraju et al., } \\
2017\end{array}$ \\
\hline & Equine & & & \\
\hline 1 & & $\begin{array}{l}\text { PAD16, } \\
\text { DNAJC16B, } \\
\text { DCDC2, CTTN, } \\
\text { REEP6, ARID5B, } \\
\text { ATG12 }\end{array}$ & Spermatozoal cells & Das et al., 2013 \\
\hline & Human & & & \\
\hline 1 & & $\begin{array}{l}\text { Protamine1, } \\
\text { Protamine 2, CD45, } \\
\text { C-Kit, } \\
\text { C-myc, E-cadherin, } \\
\text { NOS, eNOS }\end{array}$ & Spermatozoal cells & $\begin{array}{l}\text { Lambard et al., } \\
2004\end{array}$ \\
\hline 2 & & $\begin{array}{l}\text { TCP11, TESK1, } \\
\text { TSPYL1, ADAD1 }\end{array}$ & Spermatozoal cells & Bansal et al., 2015 \\
\hline
\end{tabular}




\section{Relation of sperm RNA with oogenesis}

Retention of RNA in spermatozoa seems to have an equivalent comparison with oogenesis, where mRNA is stored in large quantities until the termination of transcription (Briggs et al., 1999). To support protein synthesis, maturing oocytes depends upon the translational stocks of maternal mRNA.

Translation modification in case of both the gametes is same, where there should be equal changes in case of poly-A-tail which is having synchronization with active associations between appropriate binding proteins of RNA and untranslated regions of RNA (Kleene, 1996; Hecht, 1998; DeJong, 2006). Spermatozoal ejaculate contains two populations of mRNA which have their own functions:

A centriolar population which maintainsthe embryo and also has some role in development and

A nuclear population which helps in supporting either repacking of chromatin of 'spent' proteins transitional replacement.

\section{Relation of sperm RNA with embryonic development}

By analyzing a group of RNAs which are specific to sperm and which got delivered into the oocyte, the role of these RNAs in the fertilization process in eggs is not clear (Ostermeier et al., 2004).

Different sets of mRNAs have been found to have relationship with various functions like repackaging of chromatin, genome imprinting and development of spermatozoa. However, the particular sets of genes for predicting differences in fertility need to be analyzed (Miller et al., 2005).

\section{Association of sperm RNA with fertility}

Active miRNAs are present in massive amount in spermatozoa, and it has been evident that precise sperm borne miRNAs have correlation with fertility. Hence, the potency of spermatozoa to promote and sustain the development of zygote, embryo and fetus and also for considering male fertility, spermatozoal expression profiling could be helpful. The differences in amounts of different miRNAs between their ejaculates, helps to identify the animals with sub-fertile to high-fertile nature (Fagerlind et al., 2015).

Earlier it was presumed that the mature spermatozoal RNA undergoes certain cellular modifications during spermiogenesis; hence RNAs are either degraded or lost. In older days, spermatozoal RNA is considered as non-functional in nature, but present scenario is that the spermatozoal RNA have active functions when it enters into oocyte, during fertilization and also within the cell itself (Miller et al., 2005; Miller, 2011). Spermatozoa have an active translation of stored mRNAs (Gur and Breitbart, 2006), and also have the capacity to take up a foreign RNA and DNA, this activity can be used for the production of transgenic animals (Spadafora, 1998).

This phenomenon of transgenic production arises due to the process of apoptosis which leads to spermatozoal chromatin autodigestion (Maione et al., 1997; Sotolongo et al., 2003). Competent DNA templates transcribe to fresh RNA which appears to be histone bound. This happens because of three reasons,

Presence of enormous transcription factors (Pittoggi et al., 2001)

Spermatozoa having RNA polymerase (Hecht and Williams, 1978) and 
By means of enzyme mediated process in case of cells, RNA can be converted to DNA and there should be a possibility that DNA can also be converted to RNA (Sciamanna et al., 2003).

\section{Spermatozoal RNA as a marker for fertility research}

Spermatozoal RNA reflects the spermatogenic perspective of testis, so it can be used as a probable indicator for various infertility studies (Ostermeier et al., 2005). But prediction of infertility issues with the help of advanced molecular level studies is deficit (Balen and Jacobs, 2003). However, techniques like SAGE, microarray and various other techniques can also be used for characterization of sperm RNAs and also to study the comparison between sub-fertile and high-fertile males. (Wang et al., 2004).

\section{Potential mRNA markers for sperm quality}

Spermatozoal motility can be used as a good indicator of male fertility, and it appears to have certain molecular associations which can be determined using real time PCR based studies. Protamine 1 (PRM1) expression was noticed in spermatozoal population harvested from Percoll gradient, which was having poor motility. Same expression pattern was observed in case of both neuronal mRNAs (nNOS) and endothelial mRNAs (eNOS) (Lambard et al., 2004). Around 5000 transcripts present in spermatozoa (Ostermeier et al., 2002), can give a considerable information (Table 2) about the fertility by means of understanding molecular events, necessary for spermatogenesis.

The analysis of spermatozoal RNA (a noninvasive technique) can be used as an efficient technique to analyze male fertility, with the help of only the semen samples. The collection of semen sample to study spermatozoal RNA profiling is of great ease when compared to other techniques, which requires testes tissue biopsy. The collection of testis tissue for examination may sometimes cause a permanent damage to the testis. Hence, analyzing the spermatozoal mRNA transcripts (sperm transcriptomics) is found to be an emerging and promising technique for analyzing male fertility. With the advent of sperm transcriptomics, screening and selection of male breeding stock can be done at an early stage. Sperm transcriptomics can serve as an ideal and efficient technique, in the future, for selection of efficient male breeding stock.

\section{References}

Arangasamy, A., Kasi Manickam, V. R., DeJarnette, J. M. and Kasimanickam, R.K. (2011). Association of CRISP2, CCT8, PEBP1 mRNA abundance in sperm and sire conception rate in Holstein bulls. Theriogenology.76:570577.

Balen, A. H. and Jacobs, H.S. (2003). Infertility in Practice. Reproductive medicine and Assisted reproductive techniques series. 291-314.

Bansal, S. K., Gupta, N., Sankhwar, S. N. and Rajender, S. (2015). Differential genes expression between fertile and infertile spermatozoa revealed by transcriptome analysis. PLoS ONE. 10(5):1-21.

Bissonnette, N., Le' vesque-Sergerie, J.P., Thibault, C. and Boissonneault, G. (2009). Spermatozoal transcriptome profiling for bull sperm motility: a potential tool to evaluate semen quality. Reproduction.138:65-80.

Boerke, A., Dieleman, S. J. and Gadella, B. M. (2007). A possible role for sperm RNA in early embryo development. Theriogenology.68 (1):147-155. 
Borges, F., Gomes, G., Gardner, R., Moreno, N., McCormick, S., Feijo, J. A. and Becker, J. D. (2008). Comparative transcriptomics of Arabidopsis sperm cells. Plant Physiology. 148:1168-1181.

Briggs, D., Miller, D. and Gosden, R. (1999). Molecular biology of female gametogenesis. In Fauser BCJM (ed.) Molecular Biology in Reproductive Medicine. 251-271.

Caldwell, K. A. and Handel, M. A. (1991). Protamine transcript sharing among post meiotic spermatids. Proceedings of the National Academy of Sciences of the United States of America. 88:24072411.

Card, C., Anderson, E. J., Zamberlan, S., Krieger, K. B., Kaproth, M. and Sartini, B. L. (2013). Cryopreserved bovine spermatozoal transcript profile as revealed by high-throughput ribonucleic acid sequencing. Biology of Reproduction. 88(2):49, 1-9

Carreau, S., Lambard, S., Said, L., Saad, A. and Galeraud-Denis, I. (2007) RNA dynamics of fertile and infertile spermatozoa. Biochemical Society Transactions.35: 634-636.

Concha, I. I., Urzua, U., Yanez, A., Schroeder. R., Pessot, C. and Burzio, L. O. (1993). U1 and U2 snRNA are localized in the sperm nucleus. Experimental Cell Research. 204:37881.

Curry, E., Safranski, T. J. and Pratt, S. L. (2011). Differential expression of porcine sperm microRNAs and their association with sperm morphology and motility. Theriogenology. 76:15321539.

Dadoune, J. P. (2009). Spermatozoal RNAs: what about their functions? Microscopy Research and Technique. 72: 536-551.

Dadoune, J. P., Pawlak, A., Alfonsi, M. F. and Siffroi, J. P. (2005). Identification of transcripts by macroarrays, RT-PCR and in situ hybridization in human ejaculate spermatozoa. Molecular Human Reproduction. 11(2): 133-40

Das, P. J.,Nandina, P., Ashley, G. S., Monika, V., Sankar, C. P., Charles, L. C., Dickson., Varner, D., Bhanu, C. P. and Terje, R. (2013). Stallion Sperm Transcriptome comprises functionally Coherent Coding and regulatory RNAs as revealed by Microarray analysis and RNA-seq. PLoS ONE. 8(2): e56535.

DeJong, J. (2006). Basic mechanisms for the control of germ cell gene expression. Gene. 366:39-50.

Fagerlind, M., Stalhammar, H., Olsson, B. and Klinga-Levan, K. (2015). Expression of miRNAs in bull spermatozoa correlates with fertility rates. Reproduction in Domestic Animals. 50:587-94.

Ferraz, J. S. B. and Eduardo deFelicio. (2010). Production systems - An example from Brazil. Meat Science.84(2): 238-243.

Fischer, B. E., Wasbrough, E., Meadows, L. A., Randlet, O., Dorus, S., Karr, T. L. and Russell, S. (2012). Conserved properties of Drosophila and human spermatozoal mRNA repertoires. Proceedings: Biological Sciences. 279:2636-2644.

Galeraud-Denis, I., Lambard, S. and Carreau, S. (2007). Relationship between chromatin organization, mRNAs profile and human male gamete quality. Asian Journal of Andrology. 9: 587-592.

Ganguly, I., Gaur, G. K., Sushil, K., Mandal, D. K., Mahesh, K., Umesh, S., Sunil, K. and Arjava, S. (2013). Differential expression of protamine 1 and 2 genes in mature spermatozoa of normal and motility impaired semen producing crossbred Frieswal (HF _ Sahiwal) bulls. Research in veterinary science. 94: 256-262. 
Garrido, N., Martinez-Conejero, J. A., Jauregui, J., Horcajadas, J. A., Simon, C., Remohi, J. and Meseguer, M. (2009). Microarray analysis in sperm from fertile and infertile men without basic sperm analysis abnormalities reveals a significantly different transcriptome. Fertility and Sterility. 91:1307-1310

Georgiadis, A.P., Kishore, A., Zorrilla, M., Jaffe, T. M., Sanfilippo, J. M., Volk, E., Rajkovic, E. and Yatsenko, A. N. (2015). High quality RNA in semen and sperm: isolation, analysis, and potential application in clinical testing. Journal of Urology. 193: 352- 359.

Gilbert, I., Bissonnette, N., Boissonneault, G., Vallee, M. and Robert, C. (2007). A molecular analysis of the population of mRNA in bovine spermatozoa. Reproduction.133:1073-1086.

Goodrich, R., Johnson, G. and Krawetz, S. A. (2007). The preparation of human spermatozoal RNA for clinical analysis. Archives of Andrology. 53:161-167.

Gur, Y. and Breitbart, H. (2006). Mammalian sperm translate nuclear-encoded proteins by mitochondrial-type ribosomes. Genes \& Development. 20:411-416.

Hecht, N. B. (1998). "Molecular mechanisms of male germ cell differentiation," Bio Essays. 20(7):555-561.

Hecht, N. B. and Williams, J. L. (1978). Synthesis of RNA by separated heads and tails from bovine spermatozoa. Biology of Reproduction. 19:573-579.

Jodar, M., Kalko, S., Castillo, J., Ballesca, J. L. and Oliva, R. (2012). Differential RNAs in the sperm cells of asthenozoospermic patients. Human Reproduction Update. 27:1431-1438.

Jodar, M., Sendler, E., Moskovtsev, S. I., Librach, C. L., Goodrich, R., Swanson, S., Hauser, R., Diamond,
M. P. and Krawetz, S. A. (2015). Absence of spermatozoa RNA elements correlates with idiopathic male infertility. Science Translational Medicine. 7(295):295re6

Kasimanickam, V. R., Kasimanickam, R. K., Kastelic, J. P. and Stevenson, J. S. (2013). Associations of adiponectin and fertility estimates in Holstein bulls. Theriogenology. 79:766-777.

Kawano, M., Kawaji, H., Grandjean, V., Kiani, J. and Rassoulzadegan, $\mathrm{M}$. (2012). Novel small noncoding RNAs inmouse spermatozoa, zygotes and early embryos. PLoS ONE. 7:e44542.

Killian, G. J., Chapman, D. A. and Rogowski, L. A. (1993). Fertility-associated proteins in Holstein bull seminal plasma. Biology of Reproduction. 49:1202-1207.

Kleene, K. C. (1996). Patterns of translational regulation in the mammalian testis. Molecular Reproduction and Development. 43:268-281.

Krawetz, S. A. (2005) Paternal contribution: new insights and future challenges. Nature Review. 6:633-642.

Kumar, G., Patel, D. and Naz, R. K. (1993). c-MYC mRNA is present in human sperm cells. Cellular \& molecular biology research. 39: 111-117.

Lalancette, C., Thibault, C., Bachand, I., Caron, N. and Bissonnette, N. (2008). Transcriptome analysis of bull semen with extreme non-return rate: use of suppression-subtractive hybridization to identify functional markers for fertility. Biology of Reproduction. 78: 618-635

Lambard, S., Galeraud-Denis, I. and Martin, G. (2004). Analysis and significance of mRNA in human ejaculated sperm from normozoospermic donors: relationship to sperm motility and capacitation. Molecular Human Reproduction. 7: 535-541. 
Lima-Souza, A., Anton, E., Mao, S., Ho, W. J. and Krawetz, S. A. (2012). A platform for evaluating spermatozoa RNA biomarkers: dysplasia of the fibrous sheath--testing the concept. Fertility and Sterility. 97:1061-1066.

Liu, W. M., Pang, R. T., Chiu, P. C., Wong, B. P., Lao, K., Lee, K. F. and Yeung, W. S. (2012). Sperm-borne microRNA$34 \mathrm{c}$ is required for the first cleavage division in mouse. Proceedings of the National Academy of Sciences of the United States of America.109:490-494.

Maione, B., Pittogi, C., Achene, L., Lorenzini, R. and Spadafora, C. (1997). Activation of endogenous nucleases in mature sperm cells upon interaction with exogenous DNA. DNA and Cell Biology. 16:1087-1097.

Miller, D. (2014).Spermatozoa RNA as a mediator of genomic plasticity. Advances in Biology. Article ID 179701, 13 pages.

Miller, D. and Ostermeier, G. C. (2006). Spermatozoal RNA: Why is it there and what does it do? Gynécologie Obstétrique \& Fertilité.34: 840-846.

Miller, D. (1997). RNA in the ejaculate spermatozoon: a window into molecular events in spermatogenesis and a record of the unusual requirements of haploid gene expression and post-meiotic equilibration. Molecular

Human Reproduction. 3:669-676.

Miller, D., Briggs, D., Snowden, H., Hamlington, J., Rollinson, S., Lilford, R. and Krawetz, S. A. (1999). A complex population of RNAs exists in human ejaculate spermatozoa: implications for understanding molecular aspects of spermiogenesis. Gene. 237:385-392.

Miller, D., Ostermeier, C and Krawetz, S. A. (2005). The controversy, potential and roles of spermatozoal RNA. Trends in Molecular medicine.11: 156-163
Miller, D., Tang, P. Z., Skinner, C. and Lilford, R. (1994).Differential RNA fingerprinting as a tool in the analysis of spermatozoal gene expression. Human Reproduction. 9:864-869.

Miller, S. C., Brett, J. Baker., Brian, C. Thomas., Steven, W. Singer. and Jillian, F. Banfield. (2011). EMIRGE: reconstruction of full-length ribosomal genes from microbial community short read sequencing data. Genome Biology. $12: \mathrm{R} 44$

Miteva, K., Valkov, N., GoncharovaPeinoval, J., Kovachev, K., Zlantarev, S., Pironcheva, G. and Russev, G. (1995). Electron microscopic data for the presence of post-meiotic gene expression in isolated ram sperm chromatin. Cytobios.88:7-10.

Montjean, D., De La Grange, P., Gentien, D., Rapinat, A., Belloc, S., Cohen-Bacrie, P., Menezo, Y. and Benkhalifa, M. (2012). Sperm transcriptome profiling in oligozoospermia. Journal of Assisted Reproduction and Genetics.29:3-10.

Ostermeier, G. C., Dix, D. J., Miller, D., Khatri, P. and Krawetz, S. A. (2002). Spermatozoal RNA profiles of normal fertile men. The Lancet. 360:772-777.

Ostermeier, G. C., Goodrich, R. J., Diamond, M. P., Dix, D. J. and Krawetz, S. A. (2005). Toward using stable spermatozoal RNAs for prognostic assessment of male factor fertility. Fertility and Sterility. 83:1687-1694.

Ostermeier, G. C., Goodrich, R. J., Moldenhauer, J. S., Diamond, M. P. and Krawetz, S. A. (2005). A suite of novel human spermatozoal RNAs. Journal of Andrology. 26:70-74.

Ostermeier, G. C., Miller, D., Huntriss, J. D., Diamond, M.P. and Krawetz, S. A. (2004). Reproductive biology: delivering spermatozoan RNA to the oocyte. Nature. 429:154. 
Parthipan, S., $\quad$ Sellappan, $\quad$ S., Lakshminarayana, S., Atul, P. K., Arunachalam, A. and Janivara, P. R. (2015).Spermatozoa input concentrations and RNA isolation methods on RNA yield and quality in bull (Bos taurus). Analytical Biochemistry.482:32-39.

Peng, H., Shi, J., Zhang, Y., Zhang, H., Liao, S., Li, W., Lei, L., Han, C., Ning, L and Cao, Y. (2012). A novel class of tRNAderived small RNAs extremely enriched in mature mouse sperm. Cell Research. 22:1609-1612.

Pessot, C. A., Brito, M., Figueroa, J., Concha, I. I., Yanez, A. and Burzio, L. O. (1989). Presence of RNA in the sperm nucleus. Biochemical and Biophysical Research Communications. 158:272278.

Pitnick, S. (2009). Sperm morphological diversity. In Sperm Biology: An Evolutionary Perspective. Academic Press. 69-149.

Pittoggi, C., Magnano, A. R., Sciamanna, I., Giordano, R., Lorenzini, R. and Spadafora, C. (2001) Specific localization of transcription factors in the chromatin of mouse mature spermatozoa. Molecular Reproduction and Development. 60:97-106.

Platts, A. E., Dix, D. J., Chemes, H. E., Thompson, K. E., Goodrich, R., Rockett, J.C., Rawe, V. Y., Quintana, S., Diamond, M. P. and Strader, L. F. (2007). Success and failure in human spermatogenesis as revealed by teratozoospermic RNAs. Human Molecular Genetics. 16:763-773.

Rando, O. J. (2012). Daddy issues: paternal effects on phenotype. Cell. 151:702708 .

Rassoulzadegan, M., Grandjean, V., Gounon, P., Vincent, S., Gillot, I. and Cuzin, F. (2006). RNA-mediated non-mendelian inheritance of an epigenetic change in the mouse. Nature. 441:469-474.

Rejon, E., Bajon, C., Blaize, A. and Robert, D. (1988). RNA in the nucleus of a motile plant spermatozoid: characterization by enzyme-gold cytochemistry and in situ hybridization. Molecular Reproduction and Development. 1:49-56.

Sciamanna, I., Barberi, L. and Martire, A. (2003). Sperm endogenous reverse transcriptase as mediator of new genetic information. Biochemical and Biophysical Research Communications.312: 1039-46.

Selvaraju, S., Sivashanmugam, P., Lakshminarayana, S., Atul, P. K. B., Krishnan, B., Arunachalam, A. and Janivara, P. R. (2017). Occurrence and functional significance of the transcriptome in bovine (Bos taurus) spermatozoa. Scientific Reports. 7:42392.

Sendler, E., Johnson, G. D., Mao, S., Goodrich, R. J., Diamond, M. P., Hauser, R. and Krawetz, S. A. Stability, delivery and functions of human spermatozoa RNAs at fertilization. Nucleic Acids Research. 41:4104-4117 (2013).

Sotolongo, B., Lino, E. and Ward, W. S. (2003). "Ability of hamster spermatozoa to digest their ownDNA," Biology of Reproduction. 69(6):20292035.

Spadafora, C. (1998). Sperm cells and foreign DNA: a controversial relation. Bioessays. 20:955-964.

Wang, H., Zhou, Z., Xu, M., Li, J., Xiao, J., $\mathrm{Xu}, \mathrm{Z}$. and Sha, J. (2004). A spermatogenesis related gene expression profile in human spermatozoa and its potential clinical applications. Journal of Molecular Medicine.82:317-324. 
Wykes, S. M., Miller, D. and Krawetz, S. A. (2000). Mammalian spermatozoal mRNAs: tools for the functional analysis of male gametes. Journal of submicroscopic cytology and pathology.32:77-81.

Wykes, S. M., Visscher, D. W. and Krawetz, S. A. (1997). Haploid transcripts persist in mature human spermatozoa. Molecular Human Reproduction. 3:1519.

Yang, C. C., Lin, Y. S., Hsu, C. C., Tsai, M. H., Wu, S.C. and Cheng, W. T. (2010). Seasonal effect on sperm messenger RNA profile of domestic swine (Sus scrofa). Animal Reproduction Science. 119:76-84.

Yang, C. C., Lin, Y. S., Hsu, C.C., Wu, S. C. and Lin, E. C. (2009). Identification and sequencing of remnant messenger
RNAs found in domestic swine (Sus scrofa) fresh ejaculated spermatozoa. Animal Reproduction Science. 113: 143-155.

Yao, Y., Robinson, A. M., Zucchi, F.C., Robbins, J. C., Babenko, O., Kovalchuk, O., Kovalchuk, I., Olson, D. M., Metz, G.A. (2014). Ancestral exposure to stress epigenetically programs preterm birth risk and adverse maternal and newborn outcomes. BMC Medicine. 7(12):121.

Yathish, H. M., Subodh, K., Prem, P. D., Rajendra, P. M., Rajni Chaudhary., Siva, K. A., Subrata, K. G., Mihir, S. and Sivamani, B. (2016). Profiling of sperm gene transcripts in crossbred (Bos taurus x Bos indicus) bulls. Animal Reproduction science. 177:25-34.

\section{How to cite this article:}

Kennady Vijayalakshmy, Dharmendra Kumar, Meenakshi Virmani, Ninan Jacob and Pradeep Kumar. 2018. Sperm Transcriptomics: An Emerging Technique to Assess Male Fertility. Int.J.Curr.Microbiol.App.Sci. 7(09): 1188-1200. doi: https://doi.org/10.20546/ijcmas.2018.709.141 